\title{
Los péptidos antimicrobianos de origen vegetal con un breve enfoque en las proteínas de transferencia de lípidos: minirevisión
}

\author{
Silvio Alejandro López-Pazos, ${ }^{1,2^{*}}$ Diana-Daniela Portela, ${ }^{2}$ Adriana Rojas ${ }^{2}$ \\ y Alejandro Chaparro-Giraldo
}

\begin{abstract}
' Universidad Colegio Mayor de Cundinamarca, Facultad de Ciencias de la Salud, calle 28 No 5B-02, PBX: (57-1) 241 8800, Bogotá D. C., Colombia
${ }^{2}$ Universidad Nacional de Colombia, Departamento de Biología, Grupo de Ingeniería Genética de Plantas, A.A. 14-490, Bogotá D. C., Colombia.

* Autor para correspondencia: salopez@unicolmayor.edu.co
\end{abstract}

\section{Antimicrobial peptides from plants with a brief focus on lipid transfer proteins: mini-review}

\begin{abstract}
Defense mechanisms in biological organisms are composed by biomolecules, an important group is the antimicrobial peptides (AMPs). AMPs are part of the non-specific and innate immunity with activity against pathogens (bacteria, fungi, viruses and protozoa). Plants (a food source) are attacked by microorganisms, although a few cause disease. Plants and pathogens have coevolved, so plants have effective resistance strategies. Pathogenesis-related proteins (PR) are part of an inducible mechanism of resistance; PRs are in high proportion in parasitized plant tissues. PRs have a molecular weight of 5-75 kDa, AMPs have less than $10 \mathrm{kDa}$ including chitinases, endoproteases, peroxidases, heveinas, oxalate oxidases, lipid transfer protein (LTP) and defensins among others. LTPs have a molecular weight of 7-10 kDa and contribute with lipid exchange between membranes; LTPs contain conserved cysteine residues and have a cationic conformation. LTPs inhibit bacteria and fungi growth by interaction with membrane phospholipids of pathogens and competition for plant receptor avoiding plant-pathogen recognition. Here, we show important considerations about this topic and perspectives in colombian commercial crops.
\end{abstract}

Keywords: Pathogenesis-related protein in plants, plant pathogen, lipid transfer peptide, vegetal disease resistance, colombian crops.

Editor: Hernández-Fernández, J.

Citation: López-Pazos, S. A., Portela D. D., Rojas, A. y Chaparro-Giraldo, A. (2014). Los péptidos antimicrobianos de origen vegetal con un breve enfoque en las proteínas de transferencia de lípidos: minirrevisión. Revista Mutis 4(1); pag. 51-61

Received: Abril 28, 2014; accepted: Junio 18, 2014; Published on line: Junio 30, 2014

Copyright: $\odot 2014$ Lopéz-Pazos et al. This is an open-access article, which permits unrestricted use, distributions and reproduction in any medium, provided the original author and source are credited

Competing Interests: The authors have no conflict of interest.

\section{Resumen}

Los sistemas de defensa de los organismos vivientes abarcan una gran gama de biomoléculas, un importante grupo de estas, son los péptidos antimicrobianos (AMP del inglés Antimicrobial Peptides). Estas péptidos forman parte de la inmunidad no específica e innata de los seres vivos y son activos contra patógenos (bacterias, hongos, virus y protozoarios). Las plantas, al ser una fuente de alimento, son atacadas por muchas clases de microorganismos, aunque solo unos pocos les pueden causar enfermedades. Las plantas 
y los organismos patógenos han coevolucionado, así las primeras han logrado estrategias efectivas de resistir el ataque de sus invasores. Las proteínas relacionadas con patogénesis (PR) hacen parte de un mecanismo inducible de resistencia, las cuales se expresan en gran proporción, en tejidos vegetales parasitados. Las PR tienen un peso molecular de entre 5 a $75 \mathrm{kDa}$, aquellas con pesos inferiores a $10 \mathrm{kDa}$ se denominan AMP, entre las que se cuentan las quitinasas, endoproteasas, peroxidasas, heveinas, oxalato oxidasas, proteínas de transferencia de lípidos (LTP del inglés Lipid Transfer Protein o Lipid Transfer Peptide) y defensinas, entre otras. Las LTP presentan un tamaño de 7-10 kDa, se caracterizan por participar en intercambio de lípidos entre membranas, ser ricas en residuos de cisteína y por poseer una conformación cationica. Las LTP tienen capacidad de inhibir el crecimiento de bacterias y de hongos por su interacción con fosfolípidos de la membrana del patógeno y también por la competencia con moléculas señalizadoras del agente invasor por el receptor de la planta, y así la LTP evitaría el reconocimiento planta-patógeno. Aquí se presentan algunas consideraciones importantes acerca de esta temática y su perspectiva en la agricultura comercial colombiana.

Palabras clave: proteína relacionada con patogénesis en plantas, fitopatógeno, péptido de transferencia de lípidos, resistencia, agricultura colombiana.

\section{Agricultura sostenible y mecanismo de defensa de las plantas}

La intención de desarrollar tecnologías reproducibles, basadas en el concepto de agricultura sostenible, ha estado en el pensamiento humano desde hace varias décadas. Se considera necesario tener prácticas que no afecten los ecosistemas naturales, que sean fácilmente accesibles para los agricultores y que tengan efectos importantes en productividad produciendo bienes y servicios ecológicamente sostenibles. Es importante que estos métodos sean sostenibles en el tiempo y puedan resistir los diferentes tipos de problemas agrícolas. Se ha registrado un incremento considerable en la producción agrícola mundial (desde los años 60 ) en alrededor del $200 \%$, pero asimismo la población mundial demandante de alimentos ha crecido a más de 6 mil millones de personas (Pretty, 2008). Es deseable tener un modelo de agricultura sosteni- ble en relación con el medioambiente (asociado con nutrientes, recursos hídricos o manejo de malezas), en un esquema donde se combinen el cuidado de los ecosistemas, el manejo de enfermedades y plagas, el uso racional de la biodiversidad, la utilización de recursos genéticos y la normatividad asociada (Cheatham et al., 2009; Shennan, 2008).

Entre los principios importantes de la agricultura sostenible tenemos el uso de programas de manejo biológico y ecológico integrado para reciclado o fijación de nutrientes, uso adecuado del suelo, alelopatía, competencia, depredación y parasitismo, minimización del uso de recursos no renovables, aproximación del conocimiento y tecnología a los agricultores que los hagan sostenibles en las generaciones y aumento de las capacidades de los colectivos para afrontar los inconvenientes relacionados con plagas y enfermedades, disponibilidad de agua, manejo de bosques y recursos económicos (Pretty, 2008). La utilización racional de productos generados a partir de las interacciones bióticas y abióticas es un factor clave que puede llevar a aumentar la productividad, eliminando la necesidad de insumos externos al entorno agroecológico, llevando a una agricultura sostenible. Los disturbios biológicos son variables en los agroecosistemas que pueden llevar a un uso inadecuado de herbicidas e insecticidas químicos.

Las plantas son organismos vivos autosuficientes, que fabrican su propio alimento por medio de la fotosíntesis, y pueden habitar en la tierra o en el agua. Estos organismos producen oxígeno, necesario para la supervivencia de los seres vivos. Las plantas han sido utilizadas como fuente de alimento para el hombre, lo que llevó al desarrollo de la agricultura. Uno de los problemas más importantes en la agricultura comercial son las enfermedades de las plantas debidas a fenómenos de competencia por nutrientes, los patógenos pueden causar elevadas pérdidas que afectan de manera importante este renglón económico (Jaggard et al., 2010; Wally \& Punja, 2010; Shennan, 2008). Debido a su función vital, las enfermedades que atacan a las plantas afectan al hombre, ya que compiten con él por esta fuente de alimento, causando perjuicios económicos a la agricultura mundial. Una determinada planta es susceptible si, siendo incapaz de reconocer al patógeno, puede servir de hospedero permitiendo su penetración y con esto, la aparición de síntomas característicos. En contraste, la resistencia está cons- 
tituida por todos aquellos mecanismos de la planta para reconocer al patógeno y oponerse a la infección, los cuales pueden ser constitutivos o inducidos, dependiendo de la genética o el medio ambiente (Joshi \& Nayak, 2013; Qi \& Innes, 2013; López, 2007).

El uso de productos para el manejo de enfermedades representa elevados costos totales de producción de los cultivos, siendo por tradición una alternativa ante los problemas fitosanitarios (Wally \& Punja, 2010, Agrios, 2005).

En su ambiente natural las plantas están continuamente sometidas al contacto con diversos tipos de microorganismos, sin embargo, solo una pequeña parte de ellos puede llegar a causarles enfermedades. De este modo, las plantas y sus patógenos han coevolucionado, generando en los microorganismos formas más eficientes de colonizar a su huésped y en las plantas estrategias efectivas para resistir el ataque de sus invasores (Karasov et al., 2014; Qi \& Innes, 2013; López, 2007). Para que una planta sea capaz de responder ante el ataque de un patógeno es necesario que inicialmente sea capaz de reconocerlo. Para ello la planta se sirve de dos diferentes vías de reconocimiento que detectan, por una parte patrones moleculares asociados a microorganismos (MAMP por sus siglas en inglés), conocida como resistencia basal; y por otra parte efectores del patógeno, denominada resistencia no hospedero. Una vez que se ha reconocido la presencia del organismo invasor la planta puede desplegar su arsenal de defensa y resistir a la enfermedad (Joshi \& Nayak, 2013; Qi \& Innes, 2013; López, 2007).

En las plantas, la generación de resistencia a enfermedades se logra gracias a barreras preformadas físicas (pared celular, cutícula, depósitos de lignina) y químicas (fitoanticipinas, compuestos fenólicos, taninos, saponinas) eficientes, y a mecanismos de defensa inducibles, igualmente físicos y químicos, que se activan tras el ataque de un organismo patógeno. Dentro de los mecanismos inducibles químicos de resistencia encontramos la producción de especies oxígeno reactivas, la respuesta de hipersensibilidad, acumulación de fitoalexinas, taninos y compuestos fenólicos y la producción de proteínas relacionadas con patogénesis (PR) (Karasov et al., 2014; Dobson et al., 2013; Joshi \& Nayak, 2013; Qi \& Innes, 2013; Chehab et al., 2008; De Paula et al., 2008; Odintsova et al, 2008; Sels et al., 2008; Tavares et al., 2008). En este documento se pretende exponer una descripción de algunos aspectos relevantes asociados con la subclase peptídica de PR asociada a resistencia a enfermedades vegetales, con enfoque en PR de transferencia de lípidos, y algunas consideraciones con relación a la agricultura colombiana.

\section{Péptidos antimicrobianos}

Dentro de los sistemas de defensa de organismos tales como insectos, anfibios, mamíferos y plantas se pueden destacar los péptidos antimicrobianos (AMP por el inglés Antimicrobial Peptides). Han sido identificados en una amplia variedad de organismos, incluyendo arqueas y bacterias, lo que deja entrever su presencia temprana en la evolución (Nawrot et al., 2014; Rustagi et al., 2014; Dobson et al., 2013; NgChoi et al., 2013; Zhu, 2007). Los AMP hacen parte de la inmunidad no especifica e innata de los hospederos, los cuales pueden ser considerados antibióticos endógenos y moléculas efectoras. Se ha postulado que su principal papel se constituye en la desestabilización de la membrana celular. Estos compuestos biológicos poseen una amplia diversidad en cuanto a su actividad biológica, puesto que son activos contra patógenos que incluyen bacterias, hongos, virus y protozoarios. Su espectro de actividad es medianamente específico para cada péptido, de tal manera que la sola sustitución en un residuo podría alterar su funcionalidad. Su carácter es anfipático, lo cual está implicado en su acción biológica (Rustagi et al., 2014; Sels et al., 2008).

Los AMP varían en tamaño desde unos pocos aminoácidos hasta varias decenas de ellos, varios AMP han sido estudiados y al parecer están ampliamente distribuidos en la naturaleza, con los proyectos de genómica se ha encontrado que algunos organismos pueden llegar a tener hasta 1000 diferentes AMP. Podemos encontrar un grupo muy amplio de AMP que son ricos en cisteína y con dos tipos de naturaleza aniónica (péptidos lineares ricos en glutamina y ácido aspártico) y catiónica (ricos en prolina, arginina, histidina, fenilalanina, glicina y triptófano) y son estabilizados por puentes disulfuro. Aquellos AMP estabilizados por cisteína tienen un núcleo gamma compuesto de dos láminas beta antiparalelas. Otros péptidos tienen estructuras basadas en alfa hélices, o carecen de una estructura secundaria uniforme (Nawrot et al., 2014; Dobson et al., 2013; Ng-Choi et al., 2014; Park et al., 2007; Brogden, 2005; Ganz \& Lehrer, 1999). 
Los AMP ejercen su actividad interactuando con la membrana celular del microorganismo desestabilizándola, con un posterior efecto de lisis celular, o causando poros transitorios que le permiten al péptido ingresar al citoplasma e interactuar con moléculas receptoras que alterarían funciones fisiológicas vitales para el microorganismo, entre estas moléculas estarían proteínas involucradas en la síntesis de componentes como la pared celular, ácidos nucleicos o la traducción de proteínas (Ng-Choi et al., 2014; Maróti et al., 2011; Marlow et al., 2009; Liau et al., 2003).

Se ha encontrado que las proteínas PR se expresan en mayor proporción en tejidos vegetales parasitados y que sus pesos oscilan entre 5 a $75 \mathrm{kDa}$, así, las proteínas de pesos inferiores a 10 kDa se denominan péptidos PR, también conocidas como AMP (Carvalho \& Gomes, 2009; Carvalho \& Gomes, 2007; Thevissen et al., 2004; Thomma et al., 2002). Hacen parte de este grupo de proteínas las beta-1,3-glucanasas, quitinasas, endoproteasas, peroxidasas, heveinas, knottins, oxalato oxidasas, proteínas de transferencia de lípidos (LTP), ciclotidos, snakins, tioninas y defensinas, entre otras (Rustagi et al., 2014; Andreev et al., 2012; Kovalskaya y Hammond, 2009; De Paula et al., 2008; Sels et al, 2008). La producción de AMP es una estrategia de defensa ampliamente usada, no solo por plantas, sino también por muchos otros organismos. Los AMP son componentes de la inmunidad innata y corresponden a un antiguo mecanismo de defensa encontrado en microorganismos, hongos, plantas y animales (Verma et al., 2012; Carvalho y Gomes, 2009; Thevissen et al., 2004; Thomma et al., 2002). Los AMP no reconocen antígenos específicos, pero como ventaja, son producidos simplemente por la transcripción y traducción de un gen, se liberan relativamente rápido después de la infección con un gasto reducido de energía y biomasa (Thomma et al., 2002).

\section{Algunas clases de péptidos antimicrobianos}

Entre los AMP tenemos los inhibidores de proteasa (PR-6) que tienen un tamaño molecular de $8 \mathrm{kDa}$ y son una subclase de los inhibidores de serino-proteasa, los PR-6 tienen la propiedad de unirse a las proteasas y controlar su actividad catalítica y pueden actuar reduciendo la habilidad de su atacante para usar las enzimas líticas necesarias en la patogénesis, completar sus ciclos de reproducción u obtener nutrientes por digestión de proteínas del huésped. Además, tienen funciones involucradas en diferentes procesos bioquímicos de la planta (regulación de proteasas endógenas, movilización de proteínas de reserva) aparte de su función defensiva (Sels et al., 2008).

Otro grupo de AMP lo constituyen las defensinas (PR12), péptidos que poseen entre 45-54 aminoácidos los cuales son altamente básicos, ricos en cisteína y estructuralmente relacionados con defensinas de organismos como insectos y mamíferos, y su expresión puede ser constitutiva o inducida tras un estimulo (Figura 1) (De Paula et al., 2008; Jha et al., 2009; Anuradha et al., 2008). En vegetales las defensinas están implicadas en la respuesta a estrés biótico y abiótico tales como los que generan los hongos o las bacterias. Su actividad biológica va desde la inhibición de proteasas y amilasas, hasta bloqueo de canales iónicos e inhibición de la síntesis de proteínas (Odintsova et al., 2008). Su efecto más destacado es la inhibición del crecimiento en hongos filamentosos y levaduras (Sels et al., 2008; Solis et al., 2007).

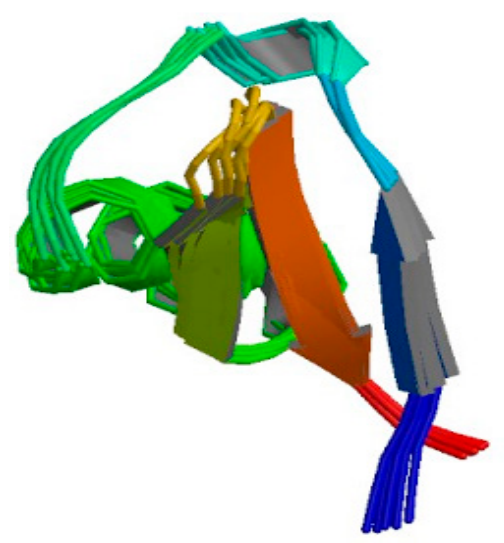

Figura 1. Estructura tridimensional de la defensina de una clase de fríjol (poroto chino) Vigna radiata. La molécula esta formada por alfa hélices y láminas beta. (Tomado de Protein Data Bank, 1TI5).

Las tioninas (PR-13) son péptidos pequeños (5kDa), generalmente básicos y ricos en cisteína; su principal característica es su actividad antifúngica y antibacteriana in vitro y de forma similar a las defensinas, su efecto antimicrobiano consiste en la permeabilización de la membrana celular del patógeno. Además se potencializan en combinación con transferasas de lípidos (Sels et al., 2008). 


\section{Proteínas de transferencia de lípidos}

Entre los AMP más importantes identificados en plantas se encuentran las proteínas de transferencia de lípidos (LTP por el inglés Lipid Transfer Protein) (o PR14), identificados inicialmente en 1975 en tubérculos de papa (Kader, 1975), posteriormente su presencia fue común en plantas florales, destacándose desde entonces por participar en la formación de la cutícula, modulación del crecimiento, desarrollo de las plantas, transferencia de lípidos entre fracciones microsomales y mitocondrias y la inducción de la señalización de defensa (Fan et al., 2013; Lei et al., 2013; Yeats y Rose, 2008). Una planta puede contener una docena de genes LTP de actividad antimicrobiana (Terras et al., 1992; Molina y García-Olmedo, 1993; Segura et al., 1993; Cammue et al., 1992). En una estructura vegetal puede existir una docena de genes de este tipo con actividad antimicrobiana como se ha evidenciado en tejidos de rábano (Raphanus sativus), espinaca (Spinacia oleracea), cebolla (Allium cepa), Arabidopsis thaliana y lenteja (Lens culinaris) entre otros (Gizatullina et al., 2013; Yeats \& Rose, 2008).

Los LTP presentan un peso molecular de 7-10 kDa, (70-95 aminoácidos), contienen un péptido señal de 21 a 35 aminoácidos, un péptido maduro de 35-74 aminoácidos. Se caracterizan por ser catiónicas, tienen un alto punto isoeléctrico (9 a 10) y un patrón conservado de cuatro puentes disulfuro entre ocho residuos de cisteína conservados que forman dos motivos: Treonina/Serina-X1-X2-Aspartato-Arginina/Lisina y Prolina-Tirosina-X-Isoleucina-Serina. Se denominaron de esta forma por su capacidad de facilitar la transferencia de fosfolípidos entre membranas in vitro, tales como fosfatidilinositol, fosfatidilcolina y galactolípidos, lo que evidencia baja especificidad y hace que estos péptidos reciban también el nombre de proteínas transferasas de lípidos inespecíficas. Su expresión ocurre como respuesta a una infección en la planta. Su actividad protectora se relaciona con el ensamblaje de cera y cutina, beta oxidación y señalización de defensa. Su conformación estructural se caracteriza por poseer una cavidad central hidrofóbica rodeada por estructuras alfa hélice y comprende el sitio de interacción entre la proteína y el grupo de lípidos específico (Glicerol, acyl CoA, ácidos grasos, esteroles). Existen dos tipos de péptidos, las LTP 1 las cuales presentan un peso molecular de $10 \mathrm{kDa}$ y una longitud de 90 a 95 aminoácidos, y las LTP 2 que poseen un peso molecular de aproximadamente $7 \mathrm{kDa}$ y una longitud de 70 aminoácidos (Gizatullina et al., 2013; Yeats \& Rose, 2008, Carvalho \& Gomes, 2007; Douliez et al., 2000; Zachowsky et al., 1998).

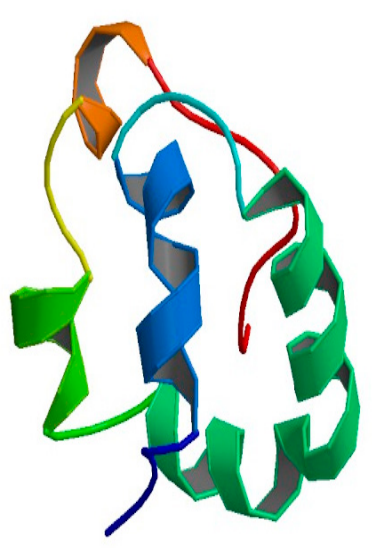

Figura 2. Estructura tridimensional de una LTP de arroz. La molécula esta formada por alfa hélices que forman una cavidad hidrofobica que sería importante en su actividad. (Tomado de Protein Data Bank, 1L6H).

La capacidad antimicrobiana de las LTP 2 no ha sido identificada. Las LTP 1 tienen capacidad de inhibir el crecimiento de bacterias y de hongos, se cree que gracias a la capacidad de interactuar con los fosfolípidos promueven la permeabilización de la membrana de los patógenos y además poseen la capacidad de competir con las moléculas señalizadoras de los patógenos por el receptor de la planta y así bloquear la interacción entre planta-patógeno (Gizatullina et al., 2013; Lei et al., 2013; Tousheh et al., 2013; Yeats y Rose, 2008; Jayaraj \& Punja, 2007; Molina \& García-Olmedo, 1993).

Se ha evidenciado que las LTP presentan actividad biológica sobre los hongos Fusarium oxysiporum, Botrytis cinerea, Sclerotinia sclerotiorum, Magnaporthe grisea o F. culmorum, también sobre las bacterias $B a-$ cillus megatherium, Erwinia caratovora, Pseudomonas solanacearum, P. syringae o el oomicete Phythoptora parasítica (Fan et al., 2013; Li et al., 2010; Yeats \& Rose, 2008; Cammue et al., 1995). Varias LTP se han producido de forma recombinante (Fan et al., 2013; Gizatullina et al., 2013; Lei et al., 2013; Tousheh et al., 2013; Sels et al., 2008).

\section{Conclusiones y perspectivas hacia Colombia}

En Colombia los patógenos (hongos, bacterias, virus y nemátodos) constituyen uno de los factores más limitantes de la agricultura, situación que se ve incremen- 
tada gracias a la carencia de cultivares comerciales con resistencia genética específica, la poca efectividad de las prácticas de control empleadas por el agricultor y el uso indiscriminado de productos químicos que inducen la mutabilidad de los patógenos hacia razas más virulentas (Uribe et al., 2011; Vallejo, 1999).

La agricultura colombiana, como en cualquier país, es uno de los ejes fundamentales en el desarrollo socioeconómico, aportando al PIB 24.051 millones de pesos para el 2009 , con un aumento del $27,4 \%$ con respecto al año 2000; las exportaciones de este sector corresponden al 30\% del total de exportaciones colombianas. El Ministerio de Agricultura de Colombia ha establecido una serie de 24 cadenas en el sector agropecuario para el año 2011, con una definición de 40 productos de valor agregado con las siguientes condiciones: tienen un mayor precio de venta, poseen algún grado de transformación, al producto tradicional se le han realizado procedimiento adicionales, y han sido producidos bajo condiciones especiales que le otorgan al producto características específicas y diferenciadoras. En general, el Ministerio de Agricultura colombiano ha definido varias áreas de intervención en la agricultura comercial: mejoramiento genético y biotecnología agrícola, manejo integral del cultivo, poscosecha, agroindustria y desarrollo de mercados, manejo integrado de plagas y enfermedades, desarrollo territorial y agroecosistemas tropicales (para más información ver https://www.minagricultura.gov.co/ Paginas/inicio.aspx). Así se necesita que como resultado de un sistema de ciencia y tecnología e innovación consolidado, se genere material vegetal adaptado a las condiciones agroecológicas particulares de nuestros ecosistemas, con una base genética de buena calidad traducida en variedades con tolerancia o resistencia a patógenos y a cambios climáticos. En el contexto de enfermedades, las cadenas productivas agropecuarias definidas por el Ministerio de Agricultura han colocado relevancia en ciertas necesidades. Dentro de la cadena del algodón se considera que variedades genéticamente modificadas pueden ser útiles para aumentar rendimientos y mejorar la economía del cultivo (en especial para resistencia a plagas y enfermedades); con el ají se ha encontrado que el uso de genes de resistencia provenientes de materiales de la Amazonía puede generar variedades que soportan el ataque de patógenos como Phytophthora spp., Fusarium spp., o bacteriosis, lo cual sería provechoso para las familias productoras del Valle del Cauca y de la costa Atlántica. Para el sector de las flores es claro que el uso de estrategias biotecnológicas generará variedades con fenotipos especiales y resistencia a patógenos o plagas (Uribe et al., 2011).

Varias son las problemáticas relacionadas con fitopatógenos que afectan las cadenas productivas agropecuarias en Colombia, y en este apartado se describen algunas por su importancia económica o de tradición para el país, y porque los agentes patógenos que las afectan son bacterianos y fúngicos susceptibles de ser controlados con AMP, y en especial con LTP dada su actividad biológica relevante sobre este tipo de microorganismos (incluyendo géneros o especies sobre los que ya se ha reportado su letalidad). Por ejemplo, el cultivo de la papa es la principal actividad agrícola de las zonas andinas en Colombia desarrollada por cerca de 90.000 familias. Se caracteriza por el uso intensivo de fertilizantes y plaguicidas, alta demanda de mano de obra rural no calificada, y por ser un cultivo disperso, aislado, de pequeños productores con limitado acceso a la tecnología. Los costos directos del cultivo corresponden al $83 \%$ del costo total, dentro de los cuales el $57 \%$ corresponde al gasto en los insumos. Los fertilizantes constituyen el $40 \%$ del valor de los insumos y $18 \%$ del costo total, seguido por el costo de la semilla con el $23 \%$ y los insecticidas con el $14 \%$ del costo de los insumos. La mano de obra con el $62 \%$ y el transporte con el $29 \%$ corresponden a los otros costos directos (43\% de los costos directos), dejando tan solo un $9 \%$ de los mismos a la preparación del suelo. El costo de mano de obra se constituye en el ítem que mayor porcentaje representa de los costos totales $(22 \%)$. En cuanto a los costos indirectos (17\% de los costos totales), el mayor monto lo ocupan los costos financieros con el $38 \%$ de los mismos, seguido por los imprevistos con el $18 \%$. Se han encontrado sobrecostos por uso irracional de agroquímicos con niveles entre $47 \%$ y $60 \%$, que representa cerca del $10 \%$ de los costos totales de producción (Ministerio de Agricultura y Desarrollo Rural, 2012; Fedepapa, 2010; Martínez et al., 2006). El cultivo del plátano en Colombia se ha visto drásticamente afectado por la presencia y ataque de enfermedades como la sigatoka negra (hongo Micosphaerella fijiensis), bacteriosis (bacteria Erwinia chrysantemi pvr. paradisiaca), y el moko (bacteria Ralstonia solanacearum). El cultivo del maíz es afectado por varias fitopatógenos favorecidos por condiciones ambientales, la clase de suelo, la susceptibilidad de los materiales $y$, en el caso de las enfermedades 
virales, por los factores que promueven la migración y establecimiento de los vectores; las enfermedades foliares son causadas por hongos como Phyllachora maydis, Monographella maydis, y Coniothyrium phyllachorae (causantes de la mancha del asfalto), el complejo Cercospora zeae y Cercospora sorghi var maydis (mancha gris) y Erwinia chrysanthemi pv. zeae (pudrición acuosa del tallo) entre otras muchas (Varón de
Agudelo y Sarria, 2007; Palencia et al., 2006), como se resume en la Tabla 1. Estas enfermedades causan pérdidas cuantiosas en campo, causando graves problemas socioeconómicos entre las familias campesinas y el aparato productivo del país (Ministerio de Agricultura y Desarrollo Rural, 2012; Fedepapa, 2010; Varón de Agudelo \& Sarria, 2007; Palencia et al., 2006; Martínez et al., 2006).

Tabla 1. Enfermedades que afectan cultivos colombianos

\begin{tabular}{|c|c|c|c|}
\hline Cultivo & Enfermedad & Patógeno & Tipo de patógeno \\
\hline \multirow{3}{*}{ Plátano } & Sigatoka negra & Micosphaerella fi jiensis & Hongo \\
\hline & Bacteriosis & $\begin{array}{l}\text { Erwinia chrysantemi pvr. para- } \\
\text { disiaca }\end{array}$ & Bacteria \\
\hline & Moko & Ralstonia solanacearum & Bacteria \\
\hline \multirow{4}{*}{ Café } & Roya, & Hemileia vastratix & Hongo \\
\hline & Las llagas del tallo & Ceratocystis fimbriata & Hongo \\
\hline & Las llagas de las raíces & Rosellinia bunodes & Hongo \\
\hline & La mancha de hierro & Cercospora coffeicola & Hongo \\
\hline \multirow{3}{*}{ Caña de azúcar } & Muermo rojo & Colletotrichum falcatum & Hongo \\
\hline & Mal de piña & Ceratocystis paradoja & Hongo \\
\hline & Pudrición de las raíces & Pythium graminicola & Hongo \\
\hline \multirow{6}{*}{ Maíz } & & Phyllachora maydis & \\
\hline & Mancha de asfalto & Monographella maydis & Hongo \\
\hline & & Coniothyrium phyllachorae & \\
\hline & Mancha gris & $\begin{array}{l}\text { Cercospora zeae maydis } \\
\text { Cercospora sorghi }\end{array}$ & Hongo \\
\hline & Mancha parda & Phaeosphaeria maydis & Hongo \\
\hline & Pudrición acuosa del tallo & Erwinia chrysanthemi pv zeae & Bacteria \\
\hline Papa & Pudrición blanda & Erwinia caratovora & Bacteria \\
\hline Yuca & Pudrición de las raíces & Phythoptora spp. & Hongo \\
\hline
\end{tabular}

En este sentido, se entiende que los LTP vegetales son un grupo de proteínas relacionadas con resistencia de gran importancia para el control de patógenos (principalmente bacterias y hongos por la evidencia experimental), que se han identificado y aplicado en la agricultura comercial, remarcándose sus posibilidades en el manejo de microorganismos patógenos en di- versos campos: medicina, industria alimenticia, salud animal y biotecnología, entre otros (Gizatullina et al., 2013; Yeats \& Rose, 2008, Carvalho y Gomes, 2007). Así, es necesario identificar la presencia de genes que codifiquen para LTP, desde DNA vegetal de la biodiversidad colombiana (nuestro país es uno de los más megadiversos del planeta), con la visión de obtener 
una opción que permita controlar patógenos dañinos para la agricultura colombiana, alcanzar la comprensión detallada de los mecanismos involucrados en la actividad biológica de las LTP, y lograr su utilización mediante bioproductos de aspersión o transgénesis vegetal en variedades colombianas económicamente importantes entre otras alternativas (Fan et al., 2013; Gizatullina et al., 2013). Algunos estudios han reportado efectos alergénicos de las LTP (Gandolfo-Cano et al., 2012; Pascal et al., 2012), por lo cual sería necesario realizar evaluaciones de bioseguridad antes de utilizar esta interesante biomolécula a gran escala en la agricultura colombiana, entre las que se incluirían factores relacionados con flujo de genes (en el caso de variedades vegetales genéticamente modificadas a aquellas que no lo son), impacto en la salud humana (agricultores y consumidores en términos de alergenicidad y toxicidad) o evolución de resistencia en los patógenos (similar a lo que se considera en el contexto de control de insectos con genes cry de $B$. thuringiensis).

\section{Referencias}

Agrios, G. N. (2005). Plant Pathology. 5th eds.

Andreev, Y. A., Korostyleva, T. V., Slavokhotova, A. A., Rogozhin, E. A., Utkina, L. L., Vassilevski, A. A., Grishin, E. V., Egorov, T. A., \& Odintsova, T. I. (2012). Genes encoding hevein-like defense peptides in wheat: distribution, evolution, and role in stress response. Biochimie. 94:1009-1016.

Anuradha, T. S., Divya, K., Jami, S. K., \& Kirti, P. B. (2008). Transgenic tobacco and peanut plants expressing a mustard defensin show resistance to fungal pathogens. Plant Cell Reports, 27(11), 17771786.

Brogden, K. A. (2005). Antimicrobial peptides: pore formers or metabolic inhibitors in bacteria? $\mathrm{Na}$ ture Reviews Microbiology, 3(3), 238-250.

Cammue, B. P., De Bolle, M. F., Terras, F. R., Proost, P., Van Damme, J., Rees, S. B., \& Broekaert, W. F. (1992). Isolation and characterization of a novel class of plant antimicrobial peptides form Mirabilis jalapa L. seeds. Journal of Biological Chemistry, 267(4), 2228-2233.
Cammue, B. P. A., Thevissen, K., Hendriks, M., Eggermont, K., Goderis, I. J., Proost, P., \& Broekaert, W. F. (1995). A potent antimicrobial protein from onion seeds showing sequence homology to plant lipid transfer proteins. Plant Physiology, 109(2), 445-455.

Carvalho, A. D. O., \& Gomes, V. M. (2007). Role of plant lipid transfer proteins in plant cell physiology-a concise review. Peptides, 28(5), 1144-1153.

Carvalho, A. D. O., \& Gomes, V. M. (2009). Plant defensins-prospects for the biological functions and biotechnological properties. Peptides, 30(5), 1007-1020.

Cheatham, M. R., Rouse, M. N., Esker, P. D., Ignacio, S., Pradel, W., Raymundo, R., \& Garrett, K. A. (2009). Beyond yield: Plant disease in the context of ecosystem services. Phytopathology, 99(11), 12281236.

Chehab, E. W., Kaspi, R., Savchenko, T., Rowe, H., Negre-Zakharov, F., Kliebenstein, D., \& Dehesh, K. (2008). Distinct roles of jasmonates and aldehydes in plant-defense responses. PloS One, 3(4), e1904.

De-Paula, V. S., Razzera, G., Medeiros, L., Miyamoto, C. A., Almeida, M. S., Kurtenbach, E., \& Valente, A. P. (2008). Evolutionary relationship between defensins in the Poaceae family strengthened by the characterization of new sugarcane defensins. Plant Molecular Biology, 68(4-5), 321-335.

Dobson, A. J., Purves, J., Kamysz, W., \& Rolff, J. (2013). Comparing Selection on S. aureus between Antimicrobial Peptides and Common Antibiotics. PloS One, 8(10), e76521.

Douliez, J. P., Michon, T., Elmorjani, K., \& Marion, D. (2000). Mini Review: Structure, biological and technological functions of lipid transfer proteins and indolines, the major lipid binding proteins from cereal kernels. Journal of Cereal Science, 32(1), 1-20.

Martínez, H., Pinzón, N., \& Barrios, C. (2006). La cadena de la papa en Colombia. Una mirada global de su estructura y dinámica 1991-2005. Documento de trabajo, (100). 
Fan, Y., Du, K., Gao, Y., Kong, Y., Chu, C., Sokolov, V., \& Wang, Y. (2013). Transformation of LTP gene into Brassica napus to enhance its resistance to Sclerotinia sclerotiorum. Russian Journal of Genetics, 49(4), 380-387.

Fedepapa - Federación Colombiana de Productores de Papa. (2010). Acuerdo de competitividad de la cadena agroalimentaria de la papa en Colombia. $72 \mathrm{p}$.

Gandolfo-Cano, M., González-Mancebo, E., Gonzálezde-Olano, D., Mohedano-Vicente, E., Muñoz-Garcia, E., Bartolomé, B., \& Pastor-Vargas, C. (2012). Lipid transfer proteins and thaumatins as relevant allergens in melon peel allergy. Annals of Allergy, Asthma \& Immunology. 109(3), 224-225.

Ganz, T., \& Lehrer, R. I. (1999). Antibiotic peptides from higher eukaryotes: biology and applications. Molecular Medicine Today, 5(7), 292-297.

Gizatullina, A. K., Finkina, E. I., Mineev, K. S., Melnikova, D. N., Bogdanov, I. V., Telezhinskaya, I. N., \& Ovchinnikova, T. V. (2013). Recombinant production and solution structure of lipid transfer protein from lentil Lens culinaris. Biochemical and Biophysical Research Communications, 439(4), 427432.

Jaggard, K. W., Qi, A., \& Ober, E. S. (2010). Possible changes to arable crop yields by 2050. Philosophical Transactions of the Royal Society B: Biological Sciences, 365(1554), 2835-2851.

Jayaraj, J., \& Punja, Z. K. (2007). Combined expression of chitinase and lipid transfer protein genes in transgenic carrot plants enhances resistance to foliar fungal pathogens. Plant Cell Reports, 26(9), 1539-1546.

Jha, S., Tank, H. G., Prasad, B. D., \& Chattoo, B. B. (2009). Expression of Dm-AMP1 in rice confers resistance to Magnaporthe oryzae and Rhizoctonia solani. Transgenic Research, 18(1), 59-69.

Joshi, R. K., \& Nayak, S. (2013). Perspectives of genomic diversification and molecular recombination towards R-gene evolution in plants. Physiology and Molecular Biology of Plants, 19(1), 1-9.
Kader, J. C. (1975). Proteins and the intracellular exchange of lipids: I. stimulation of phospholipid exchange between mitochondria and microsomal fractions by proteins isolated from potato tuber. Biochimica et Biophysica Acta (BBA)-Lipids and Lipid Metabolism, 380(1), 31-44.

Karasov, T. L., Horton, M. W., \& Bergelson, J. (2014). Genomic variability as a driver of plant-pathogen coevolution? Current Opinion in Plant Biology, 18, 24-30.

Kovalskaya, N., \& Hammond, R. W. (2009). Expression and functional characterization of the plant antimicrobial snakin-1 and defensin recombinant proteins. Protein Expression and Purification, 63(1), 12-17.

Lei, L., Chen, L., Shi, X., Li, Y., Wang, J., Chen, D., \& Li, Y. (2014). A Nodule-Specific Lipid Transfer Protein AsE246 Participates in Transport of Plant-Synthesized Lipids to Symbiosome Membrane and Is Essential for Nodule Organogenesis in Chinese Milk Vetch. Plant Physiology, 164(2), 1045-1058.

Li, X., Xia, B., Jiang, Y., Wu, Q., Wang, C., He, L., \& Wang, R. (2010). A new pathogenesis-related protein, LrPR4, from Lycoris radiata, and its antifungal activity against Magnaporthe grisea. Molecular Biology Reports, 37(2), 995-1001.

Liau, C. H., Lu, J. C., Prasad, V., Hsiao, H. H., You, S. J., Lee, J. T., \& Chan, M. T. (2003). The sweet pepper ferredoxin-like protein (pflp) conferred resistance against soft rot disease in Oncidium orchid. Transgenic Research, 12(3), 329-336.

López C. (2007). Fitopatología molecular. Editorial Universidad Nacional de Colombia. 145 p.

Marlow, V. L., Haag, A. F., Kobayashi, H., Fletcher, V., Scocchi, M., Walker, G. C., \& Ferguson, G. P. (2009). Essential role for the BacA protein in the uptake of a truncated eukaryotic peptide in Sinorhizobium meliloti. Journal of Bacteriology, 191(5), 15191527.

Maróti, G., Kereszt, A., Kondorosi, E., \& Mergaert, P. (2011). Natural roles of antimicrobial peptides in microbes, plants and animals. Research in Microbiology, 162(4), 363-374. 
Ministerio de Agricultura y Desarrollo Rural. (2012). Anuario Estadístico del Sector Agropecuario y Pesquero 2011. Edición: Dirección de Política Sectorial - Grupo Sistemas de Información. 204 p.

Molina, A., \& García-Olmedo, F. (1993). Developmental and pathogen-induced expression of three barley genes encoding lipid transfer proteins. The Plant Journal, 4(6), 983-991.

Nawrot, R., Zauber, H., \& Schulze, W. X. (2014). Global proteomic analysis of Chelidonium majus and $\mathrm{Co}$ rydalis cava (Papaveraceae) extracts revealed similar defense-related protein compositions. Fitoterapia, 94, 77-87.

Ng-Choi, I., Soler, M., Güell, I., Badosa, E., Cabrefiga, J., Bardaji, E., \& Feliu, L. (2014). Antimicrobial Peptides Incorporating Non-Natural Amino Acids as Agents for Plant Protection. Protein and Peptide Letters, 21(4), 357-367.

Odintsova, T. I., Rogozhin, E. A., Baranov, Y., Musolyamov, A. K., Yalpani, N., Egorov, T. A., \& Grishin, E. V. (2008). Seed defensins of barnyard grass Echinochloa crusgalli (L.) Beauv. Biochimie, 90(11), 1667-1673.

Palencia, G., Gómez, R., \& Martín, J. (2006). Manejo sostenible del cultivo del plátano. Corpoica-Corpoboyacá. Bucaramanga, Colombia.

Park, S. C., Lee, J. R., Shin, S. O., Park, Y., Lee, S. Y., \& Hahm, K. S. (2007). Characterization of a heat-stable protein with antimicrobial activity from Arabidopsis thaliana. Biochemical and Biophysical Research Communications, 362(3), 562-567.

Pascal, M., Muñoz-Cano, R., Reina, Z., Palacin, A., Vilella, R., Picado, C., \& Bartra, J. (2012). Lipid transfer protein syndrome: clinical pattern, cofactor effect and profile of molecular sensitization to plant-foods and pollens. Clinical \& Experimental Allergy, 42(10), 1529-1539.

Pretty, J. (2008). Agricultural sustainability: concepts, principles and evidence. Philosophical Transactions of the Royal Society B: Biological Sciences, 363(1491), 447-465.
Qi, D., \& Innes, R. W. (2013). Recent advances in plant NLR structure, function, localization, and signaling. Frontiers in immunology, 4.

Rustagi, A., Kumar, D., Shekhar, S., Yusuf, M. A., Misra, S., \& Sarin, N. B. (2014). Transgenic Brassica juncea Plants Expressing MsrA1, a Synthetic Cationic Antimicrobial Peptide, Exhibit Resistance to Fungal Phytopathogens. Molecular Biotechnology, 56(6), 535-545.

Segura, A., Moreno, M., \& García-Olmedo, F. (1993). Purification and antipathogenic activity of lipid transfer proteins (LTPs) from the leaves of Arabidopsis and spinach. FEBS Letters, 332(3), 243-246.

Sels, J., Mathys, J., De Coninck, B., Cammue, B., \& De Bolle, M. F. (2008). Plant pathogenesis-related (PR) proteins: a focus on PR peptides. Plant Physiology and Biochemistry, 46(11), 941-950.

Shennan, C. (2008). Biotic interactions, ecological knowledge and agriculture. Philosophical Transactions of the Royal Society B: Biological Sciences, 363(1492), 717-739.

Solis, J., Medrano, G., \& Ghislain, M. (2007). Inhibitory effect of a defensin gene from the Andean crop maca ( Lepidium meyenii) against Phytophthora infestans. Journal of Plant Physiology, 164(8), 10711082.

Tavares, L. S., Santos, M. D. O., Viccini, L. F., Moreira, J. S., Miller, R. N., \& Franco, O. L. (2008). Biotechnological potential of antimicrobial peptides from flowers. Peptides, 29(10), 1842-1851.

Terras, F. R., Schoofs, H. M., De Bolle, M. F., Van Leuven, F., Rees, S. B., Vanderleyden, J., \& Broekaert, W. F. (1992). Analysis of two novel classes of plant antifungal proteins from radish (Raphanus sativus L.) seeds. Journal of Biological Chemistry, 267(22), 15301-15309.

Thomma, B. P., Cammue, B. P., \& Thevissen, K. (2002). Plant defensins. Planta, 216(2), 193-202.

Thevissen, K., Warnecke, D. C., François, I. E., Leipelt, M., Heinz, E., Ott, C., \& Cammue, B. P. (2004). Defensins from insects and plants interact with fungal glucosylceramides. Journal of Biological Chemistry, 279(6), 3900-3905. 
Tousheh, M., Miroliaei, M., Asghar Rastegari, A., Ghaedi, K., Esmaeili, A., \& Matkowski, A. (2013). Computational evaluation on the binding affinity of non-specific lipid-transfer protein-2 with fatty acids. Computers in Biology and Medicine, 43(11), 1732-1738.

Uribe Galvis, C. P., Fonseca Rodríguez, S. L., Bernal Ramos, G. E., Contreras Pedraza, C. A., \& Castellanos Domínguez, Ó. F. (2011). Sembrando innovación para la competitividad del sector agropecuario colombiano.

Vallejo Cabrera, F. A. (1999). Mejoramiento genético y producción de tomate en Colombia.

Varón, F., \& Sarria, G. (2007). Enfermedades del maíz y su manejo. Instituto Colombiano Agropecuario. Palmira, Colombia.

Verma, S. S., Yajima, W. R., Rahman, M. H., Shah, S., Liu, J. J., Ekramoddoullah, A. K., \& Kav, N. N. (2012). A cysteine-rich antimicrobial peptide from Pinus monticola (PmAMP1) confers resistance to multiple fungal pathogens in canola (Brassica napus). Plant Molecular Biology, 79(1-2), 61-74.
Wally, O., \& Punja, Z. K. (2010). Genetic engineering for increasing fungal and bacterial disease resistance in crop plants. GM Crops, 1(4), 199-206.

Yeats, T. H., \& Rose, J. K. (2008). The biochemistry and biology of extracellular plant lipid-transfer proteins (LTPs). Protein Science, 17(2), 191-198.

Zachowski, A., Guerbette, F., Grosbois, M., Jolliot-Croquin, A., \& Kader, J. C. (1998). Characterisation of acyl binding by a plant lipid-transfer protein. European Journal of Biochemistry, 257(2), 443-448.

Zhu, S. (2007). Evidence for myxobacterial origin of eukaryotic defensins. Immunogenetics, 59(12), 949-954. 